\title{
Astúcias cegas e razões da contingência - notas sobre a reversão hegeliana
}

\section{Blind cunnings and contigency's reasons - notes on the hegelian reversal}

* Gustavo Chataignier

\begin{abstract}
Resumo: Introdutoriamente, situaremos em linhas gerais o debate contemporâneo no que tange ao hegelianismo, apontando tanto para a crítica ao sujeito legislador como para novas leituras abertas à contingência. Em um segundo momento, exporemos os argumentos presentes nos chamados "cursos de filosofia da história", evidenciando primeiramente seu princípio identitário, para em seguida problematizar a pertinência desse uso mediante os argumentos de um pensamento relacional e portanto ontologicamente dinâmico e empiricamente comparativo. Por fim, será questão de levantar a hipótese da extração de um modus operandi da letra hegeliana, sem, contudo, fazer sistema. Nesse sentido, o conceito modal de "possível" substituiria a "liberdade" em prol de uma racionalidade da contingência.
\end{abstract}

Palavras-chave: Astúcia da Razão. Historicidade. Liberdade. Contingência.

\begin{abstract}
As an introduction, contemporary debate with Hegelianism will be settled in general lines, whilst critically pointing to the legislator subject as well as to new readings opened to contingency. In a second moment, we will outline the arguments presented in the "Lectures on the Philosophy of History", first highlighting its identitary character, then problematizing the relevance of such an otherwise based usage, ie on the basis of relational thinking and therefore both ontologically dinamic and empirically comparative. Lastlly, it is a issue to raise the hypothesis of withdrawing, so to speak, a modus operandi in Hegelianism without, however, making system. In this sense, the modal concept of "possibility" would replace that of "freedom" in order to build a contingency rationallity.
\end{abstract}

Keywords: Cunning of Reason. Historicity. Freedom. Contingency.

* Doutor em filosofia pela Universidade de Paris VIII; professor adjunto do Departamento de Comunicação Social da PUC-Rio, Rio de Janeiro, Brasil; pesquisador associado ao Departamento de Filosofia da Universidade de Paris VIII; vice-líder do NuFFC/UFRJ (Núcleo de Filosofia Francesa Contemporânea).<gustavo.chat.gad@gmail.com> 


\author{
"Não sou eu quem me navega/ \\ Quem me navega é o mar" \\ (PAULINHO DA VIOLA, “Timoneiro”)
}

\title{
Introdução ${ }^{1}$ - Hegel contemporâneo?
}

Dode o aparato hegeliano engendrar diretamente, sem remanejos, 1 um "sistema da contingência"? Pode o hegelianismo responder a demandas de sentido de nosso presente histórico? Ou, pelo contrário, permanece catatônico em face de imagens pululantes e de conexões mais velozes do que a luz? Caso a relação entre a relação e a não relação, típica do hegelianismo, redundar em mera adequação, a entrada se revela contraproducente. Com a operação do princípio identitário, o espaço da relação reduzir-se-ia a uma conversão já sabida, sem imprevistos - que se pesem ainda as querelas de Marx sobre o idealismo e a crítica à "coisa da lógica", ao fim e ao cabo fiadora do Estado².

Desde o interior do labirinto hegeliano, com a visada de morar no negativo, as saídas via um cristianismo dogmático ${ }^{3}$ e loas a uma reificação espacial do Estado parecem confirmar a suspeita de que tudo se desfaz em linha reta ou em ponto final. Sobretudo se a tônica se concentra nos cursos sobre filosofia da história. Ora, sabemos que neles a filosofia se atribui a inglória tarefa de "eliminar o acaso", bem como de "se livrar do elemento natural"4. Some-se a isso o parecer presente na

1 Nota preliminar: informamos aos leitores que a maior parte das referências bibliográficas se encontra em língua francesa. Isso se deve pelo fato de que o presente artigo é fruto de nossas pesquisas realizadas na França. Todavia, as referências bibliográficas incluem as traduções brasileiras de Hegel. Por fim, a paginação correspondente da Fenomenologia do Espírito (em uma de suas edições brasileiras, abaixo indicada, nota 7) foi feita. Infelizmente tal expediente não se estendeu à Ciência da Lógica, ainda sem tradução completa por aqui - apesar do belo e recente esforço de Marco Aurélio Werle com sua seleção de excertos de 2011.

2 MARX, Karl. Critique de l'État hégélien - Manuscrit de 1843. Paris: UGE, 1976, p. 79. É sempre importante lembrar que os debates acerca da universalização de direitos não descarta, em hipótese alguma, a contribuição hegeliana a respeito da teoria do Estado. Em se assumindo a universalidade da lei, deve ela ser indiferente às diferenças, não lhes atribuindo assim identidade alguma. Contudo, se, em termos de direitos, essa leitura do Estado "deixa ser" as diferenças, no nível econômico seria, em se prosseguindo o raciocínio, questão de garantir condições de partida iguais - em nome, justamente, do livre desabrochar das faculdades individuais. O Estado é político, tal como seu funcionamento. Nisso se é, uma vez mais, de certa forma, hegeliano - ou seja, o Estado posto como racional.

3 Por dogmático intenta-se dizer teleológico. Nos apressamos, não obstante, a tecer o elogio da figura simbólica do Cristo como Sujeito, ou seja, como excesso que se separa da substância, seu Outro.

4 HEGEL, G. W. F. La Raison dans l'Histoire. Paris: UGE, 1965, p. 48 e 79. 
Enciclopédia, segundo o qual as contingências não perfazem material filosófico ${ }^{5}$.

Quiçá outros traçados, mais sinuosos, nos guiem nessa exploração. A mesma Enciclopédia logo em seguida postula o livre curso da contingência na natureza e na história ${ }^{6}$. Logo, se justifica uma releitura do conceito de "astúcia da razão": a necessidade da paixão e a presença dos grandes homens para a efetivação da história não os reduzem a fantoches. A efetividade do campo histórico é distinta das intenções e paixões de seus agentes. Lidamos com o argumento segundo o qual o que é posto pela razão deve encontrar sua morada no outro, em uma proximidade que enseja a renegociação das distâncias. A razão que não se realiza por si só abriria a via para uma leitura da filosofia da história onde os fins são distintos dos meios - onde a necessidade ganha inteligibilidade apenas a posteriori. Fins e meios devem constantemente ser reavaliados pelo pensamento autônomo que pode sair de si e prestar atenção à exterioridade, às danças das mediações ${ }^{7}$.

Ao deslocar o conceito de "astúcia da razão", reorientados pelo princípio da contingência, imprimimos uma guinada na letra hegeliana. Espera-se que o sistema opere segundo outros comandos. Por um lado, a astúcia da razão é lida como uma teoria da ação produtora de efeitos

5 HEGEL, G. W. F. Encyclopédie des sciences philosophiques, tomo I, La Science de la logique. Paris: Vrin, 1994, p. 182. O "agregado de ciências" não seria filosófico na medida em que sua unidade é exterior (dependente da filosofia) ou formada pela justaposição de ciências. Tal "ordem", explica Hegel, "deve necessariamente, pela mesma razão e ainda mais porque os materiais eles mesmos são de natureza contingente, permanecer uma tentativa e sempre mostrar lados inadequados" (Idem, ibidem).

6 Hegel enumera alguns traços daquilo que as ciências guardam de positivo, posto que se trata do regime da efetividade e das determinações da existência: "Seu começo, em si racional, passa no contingente, desde que tenham que fazer descer o universal na singularidade e na efetividade empírica. Nesse campo da variabilidade e da contingência não se pode fazer prevalecer o conceito , mas somente racionalidades. (...) Da mesma maneira a ideia da Natureza se perde em sua singularização e em contingências, e a história natural, a geografia, a medicina etc. caem em determinações da existência, em espécies e diferenças que são determinadas por um acaso exterior e pelo jogo [das coisas], não por meio da razão. A história também entra nesse caso na medida que, se a ideia é sua essência, sua aparição é, entretanto, na contingência e no campo do arbitrário" (ibidem).

7 Que se pense também na Fenomenologia do espírito, onde Hegel mostra o voltar da si das figuras da consciência a partir da imediaticidade; aí a validade das normas não é pressuposta. Nesse sentido, o falso faz parte da verdade (HEGEL, G. W. F. Phénoménologie de l'esprit, tomos I. Paris: Aubier, 1975, p. 34-35. Para a edição brasileira ver HEGEL. G. W. F. Fenomenologia do espírito. Tradução de Paulo Meneses, com a colaboração de Karl-Heinz Efken e José Nogueira Machado. Petrópolis/Bragança Paulista: Editora Vozes/Editora Universitária São Francisco, 2013, p. 45-46) - como o "caminho da dúvida" ou "caminho do desespero" (ibidem, p. 69). Observação: para o tomo II da Phénoménologie (em edição francesa), 1983. 
não previstos. Por outro, sua fundamentação de ordem sistemática repousa na problematização do conceito de liberdade, quer seja nos cursos sobre história e direito quer seja na grande Lógica. Em termos lógicos, o processo de determinação é relativamente independente dos elementos por ele determinados, uma vez que a efetivação se dá com quaisquer elementos que porventura se encontrem - o que justifica o abandono da temática da liberdade em prol da possibilidade. Não nos esqueçamos do comentário de Hyppolite, segundo o qual a reflexão é um momento positivo do absoluto que "eleva o verdadeiro a um resultado" e que "suprime" a oposição entre "o verdadeiro e seu vir a ser"8.

\section{Filosofia da história ou filosofia na história? ${ }^{9}$}

Jean Hyppolite preocupa-se com uma abertura constitutiva da história, o que o leva a destacar o papel da negatividade ao longo da produção hegeliana. A figura da "consciência infeliz" seria, assim, central. O tradutor e comentador francês acredita que um ponto chave do hegelianismo é compreender a relação entre a Fenomenologia e a Lógica, ou, em termos mais contemporâneos, entre "antropologia" e "ontologia". O desafio é ligar os processos de formação da consciência e os diversos níveis de reconhecimento com a "reflexão absoluta que passa no homem". Ora, tal ligação é a própria história, mesmo que "(...) essa passagem não seja ela mesma um fato histórico" 10 .

A história é a história da conquista do conceito por parte do espírito - não sem resistência. Seu movimento de interiorização, de surgimento da natureza em sua alteridade antropológica, é constituído por avanços e retomadas, cujo objetivo é intensificar o ponto inicial de experiência. Curiosamente, nesse sentido, não se pode propriamente falar em "progresso" na filosofia hegeliana. No tempo do espírito, condensação e expansão da experiência e de sua inteligibilidade repetem-se indefinidamente na e graças à contin-

8 HYPPOLITE, Jean. In: Phénoménologie I, p. 19-20. Talvez resida aí também a atualidade e a operacionalidade dos debates acerca do "reconhecimento", onde os momentos da dialética são inteligíveis em uma normatividade também contingente, independentemente do prosseguimento do sistema.

9 A feliz expressão "filosofia na história", em oposição à "filosofia da história" (compreendida enquanto teodiceia), é de Étienne Balibar (BALIBAR, Étienne. La Crainte des masses Politique et philosophie avant et après Marx. Paris: Galilée, 1997, p. 300). O jogo de palavras tem o mérito de dotar o espírito de efetividade na medida em que é "espacializado": algo do espaço sem a ele se reduzir, o tempo é a ausência que se manifesta no jogo das contingências.

10 HYPPOLITE, Jean. Logique et existence - Essai sur la logique de Hegel. Paris: PUF, 1991, p. 247. 
gência. A manifestação da racionalidade é imediatamente temporal $^{11}$.

Não era questão, como nas Luzes, de tão só criticar a vida no momento presente, mas de integrá-la ao conhecimento. Eis o momento em que os ventos da história adentram, mais do que nunca, no seio da especulação. A vida de então correspondia à Revolução francesa. Todavia, para se demarcar das abstrações, não bastava contar com esse acontecimento. O que explica a "coleta" de formas mais antigas de vida, como a polis grega e o império romano. Vale o mesmo para os esforços cartesianos concernentes à extensão do pensamento; junte-se a isso o espaço introduzido pelas objetividades naturais de Galileu, bem como as condições de possibilidade kantianas em oposição ao determinismo físico de Newton. Contudo, a "distância produtora" de novidade para Hegel foi a Revolução francesa. A história é a resposta à pergunta: como foi possível tal acontecimento? Como o negativo se tornou efetivo? Como do nada se tornar tudo? ${ }^{12}$

\section{Cursos sobre filosofia da história e tipos de história}

Parte-se de uma história concreta e parcelar, com o objetivo de se aportar em uma história concreta global, pela mediação do conceito. Para tanto, Hegel distingue alguns tipos de historiografia, a "história original", a "história refletida" (onde se destacam também uma "história pragmática", uma "história crítica" e as "histórias especiais"), e, finalmente, a "história filosófica" - que nega, conserva e supera os modelos anteriores.

A história original é feita, ou melhor, registrada por testemunhas oculares, cronistas participantes dos acontecimentos de seu tempo. Interiorizam as ações e as tornam exteriores por meio de seus escritos, tornando a época disponível a seus leitores, mesmo separados por longos intervalos de tempo. Contudo, tal interiorização responde apenas pela representação ou pela memória: são positividades (acontecimentos) que não trazem o espírito do passado, o que limitaria os sujeitos a uma relação exterior ${ }^{13}$. Em todo caso, essa produção é a matéria prima para qualquer pretensão historiográfica.

11 Lembremo-nos do comentário engelsiano. Mesmo que a história seja fiadora de sentido enquanto intelecção, ela não é um destino, posto que sua contingência, ainda que determinada (essa contingência, aqui), é incontornável. ENGELS, Friedrich. "La Sainte famille". In: Euvres III - Philosophie. Paris: Pléiade, 1982, p. 526.

12 CHÂTELET, François. "Hegel". In: La Philosophie et l'histoire (1780-1880) - Histoire de la philosophie, tomo V. Org. por François Châtelet, Wanda Bannour, Jean-Luc Dallemagne, Sami Naïr, Alexis Philonenko e Nicos Poulantzas. Paris: Hachette, 2000, p. 183-192.

13 D'HONDT, Jacques. Hegel - philosophie de l'histoire vivante. Paris: PUF, 1966, p. 391. 
Em contraposição ao "engajamento" da história original, e distinta da "história filosófica", a "história refletida" prima na busca pela objetividade, ou seja, por um distanciamento crítico. Ora, deter-se aos fatos responde ao funcionamento limitado do entendimento. Por outro lado, há oposição aos chamados "historiadores teológicos", uma vez que se busca o encadeamento de causas e efeitos humanos ${ }^{14}$. Por seu turno, as produções da "história crítica", embora almejem uma "objetividade superior", pecam por introduzir o presente no passado, perdendo de vista portanto o espírito do tempo. A razão de ser do pensamento é menos julgar do que explicar o erro passado - da mesma maneira que, a posteriori, o saber se reconhece já expresso na fé.

Hegel não economizou tinta com as ditas "histórias especiais": os exemplos evidentes são a filosofia do direito, a estética e a filosofia da religião. Contudo, o pensador não deixou de ter em mente a manifestação do espírito (e sua lógica de mediação) em cada domínio particular. Em suma, essas leituras não foram fragmentadas.

Uma visão de conjunto, por assim dizer, de todo o processo temporal e de todas abordagens filosófico-historiográficas é empreendida pela "história filosófica". Passado ingênuo e objetividade crítica reúnemse, eis o momento que pede a intervenção de uma história ao nível do espírito. Todo o passado é conservado e concentrado no presente, sob a forma de um "ser advindo". Jacques D'Hondt adota uma leitura colada à Fenomenologia do Espírito, visto que enxerga uma continuidade entre a referida obra e as Lições: em ambos os casos é questão de reinteriorizar o que foi exteriorizado, em novo caminhar ${ }^{15}$.

E é graças ao princípio de interiorização que o passado continua a nos influenciar. Evidentemente, cada reabsorção é já uma reorganização, o que leva a nova dicção da história e evidencia a plasticidade do tempo. O passado se faz presente, disponível e não instrumentalizado, graças ao trabalho do presente. Este, paradoxalmente, é tanto determinado quanto livre. Se se quiser, há o esquema de determinação progressiva e fundação regressiva - onde o ato de retorno aos fatos (ou a si) é performativo, ou seja, não deixa intacto o elemento analisado (e tampouco o passado, que se o diga).

A pretensão de Hegel não é das menores: ensinar uma história geral, filosófica e mundial; mais do que uma "filosofia da história", uma

${ }_{14}$ Em termos de história do pensamento, trata-se de uma crítica ao providencialismo de Bossuet, lido por Hegel, cuja inspiração residiria em Políbio: segundo o romano, a história é feita por fatos políticos e militares (ibidem, p. 382-383), de onde se extraem modelos aproximativos, com a historia magistra vitae.

15 Ibidem, p. 405. Todavia, uma leitura mais corrente enxerga o privilégio da experiência, evidenciado na Fenomenologia do Espírito, bem como as estruturas cambiantes e relacionais da grande Lógica, negligenciados nas páginas das Lições. 
"história filosófica". Ele acredita instruir o historiador de um ponto de vista universal, e não apenas subjetivo (no sentido psicológico ou, ainda, do entendimento). Sua narrativa nos leva não a um encadeamento de povos e épocas, mas ao "mundo" - ao presente do espírito. A realização do espírito acarreta, nota com certa dose de humor D'Hondt, que o espírito do mundo se faça "mundano" ${ }^{16}$. Toda a dificuldade reside em saber se a história enquanto resultado redunda em predeterminação de qualquer resultado, se a interiorização não passa de uma rotulação.

\section{Fundação a posteriori versus identidade estanque}

A duração do tempo não é unilateral ou unívoca. Equívoca e não obstante irreversível, ela é "encrustada" de oportunidades, linha sempre cortada. Mesmo a vida individual é atravessada por uma multiplicidade de ritmos: alguns lentos, como os ecológicos, e de mentalidades; outros médios, como as conjunturas; outros curtos, como o dos acontecimentos ${ }^{17}$. Isso posto, Daniel Bensaïd propõe uma releitura da combalida filosofia da história de Hegel. A universalidade não preexiste a um processo de universalização (algo está em vias de se efetivar); será apenas a posteriori que se iniciará a reflexão de uma "universalidade em devir". Esse procedimento abre o campo às preocupações empíricas de uma história e uma antropologia comparadas ${ }^{18}$. Não reconhecer a historicidade de determinada formação social não acarreta em negar-lhe reconhecimento de humanidade; antes, lida-se com diferentes simbolizações a partir da natureza, ou seja, formas distintas de mediação.

A hipótese da anterioridade do espírito em relação à natureza desabilita qualquer tentativa de problematização da história, fechando-a no finalismo. Voltaremos a esse ponto. Porém, tentaremos mostrar como a linguagem especulativa pode ludibriar leituras imediatistas.

A natureza seria simplesmente deduzida da ideia? ${ }^{19} \mathrm{O}$ encaminhamento sistemático não sugere uma exposição da lógica e uma posterior passagem à exterioridade, em processo etapista e abstrato? Um nietzscheano não teria maiores dificuldades de aí encontrar o ápice da separação metafísica platônica entre o sensível e o inteligível. Uma saída consiste em levar o idealismo a sério: não lidamos com qualquer idealismo, mas sim com o idealismo absoluto. Quer-se dizer com isso que a autorrelação no contato

16 Ibidem, p. 420, 425, 426 e 428.

17 RICEUR, Paul. Temps et récit I. Paris: Seuil, 1983, p. 250.

18 BENSAÏD, Daniel. Marx o intempestivo - grandezas e misérias de uma aventura crítica. Rio de Janeiro: Civilização Brasileira, 1999, p. 44.

19 HEGEL. G. W. F. Leçons sur la philosophie de l'histoire. Paris: Vrin, 1987, p. 32: “O sistema da lógica é o reino das sombras, o mundo das essencialidades simples, liberadas de toda concreção sensível". 
com o outro produz o outro de si. Nesse sentido, é preciso seguir à risca a ideia de pôr os pressupostos. Assim, abandona-se a linearidade do espírito que ganha a natureza e se passa ao espírito como efeito, surgido e criado a posteriori - só que enquanto verdade da natureza, ou retorno dela a um outro nível.

O espírito pressupõe a natureza. Isso é o que garante sua efetivação. É apenas nesse sentido que o espírito pode ser "primeiro", a saber, como verdade ou resultado de uma natureza superada (portanto conservada na identidade especulativa do espírito):

Essa identidade é a negatividade absoluta, porque o conceito tem na natureza sua objetividade externa consumada, porém essa sua extrusão é suprassumida, e o conceito tornou-se nela idêntico a si mesmo. Por isso o conceito só é essa identidade enquanto é retornar da natureza ${ }^{20}$.

Como comenta Žižek, o conceito tem na natureza sua exterioridade, objetiva e separada (tese); em um segundo momento, esse exterior é negado e integrado ao espírito, que atinge a autoidentidade (antítese). Finalmente, essa identidade deve ser reiterada, posto que é produção (síntese). Tal identidade é, consequentemente, negativa: ao se relacionar com seus pressupostos naturais o espírito não os apaga (negação imediata), mas, isto sim, se relaciona consigo - eis a positividade e efetividade do espírito devindo. Não é algo exterior que se acrescenta à natureza em um mau infinito. Em outras palavras, a natureza do espírito é processual; há espírito enquanto houver vir a ser; voltar a si é, portanto, criar espírito ${ }^{21}$.

Os opostos coincidem, na medida em que a oposição, externa e contingente, se resolve em relação a si negativa (o mais íntimo emerge via intrusão do real $^{22}$, em termos sintomais). Esta a razão pela qual não há mediação rumo à unidade estável. Segundo Žižek, isso explica as mudanças históricas, pois épocas e sociedades não cessarão de se exporem ao negativo ${ }^{23}$. Nessa mesma linha de análise, Jacques D'Hondt pensa que a dialética entre alienação e memória, entre Entäusserung e Erinnerung, contradiz a teoria de um "espírito mundial", pois este não teria necessidade de objetos (e portanto também da experiência) para se lembrar de $\mathrm{si}^{24}$.

20 HEGEL, G. W. F. Enciclopédia das ciências filosóficas em compêndio, tomo 3, Filosofia do espírito. São Paulo: Loyola, 1995, p. 15.

21 ŽIŽEK, Slavoj. Menos que nada - Hegel e a sombra do materialismo dialético. São Paulo: Boitempo Editorial, 2013, p. 311-312.

22 Ao contrário de Kant, que se o diga. Na Crítica do Juízo o mais íntimo (a sensação) não se revela senão por meio da razão.

${ }^{23}$ Ibidem, p. 316.

24 D'Hondt. Hegel. p. 411. 
A história empírica nos mostra que a fratura social e o sofrimento subjetivo não se prestam facilmente à reconciliação. $O$ funcionamento do espírito objetivo só poderia esperar solução no espírito absoluto, na passagem da necessidade à liberdade seguindo as figuras da religião manifesta e da filosofia. Ora, o espírito finito não comporta tal otimismo, do qual nos vemos obrigados a nos dessolidarizar. Temos boas razões para crer que o espírito finito é incapaz de se reconciliar consigo mesmo. A aposta, por outro lado, consiste na objetivação racional das instituições, o que se traduz em reconhecimento, em sucessivas aproximações.

Paralelamente, não obstante, à espontaneidade da razão que se efetiva, corresponde a infinidade da experiência. $O$ funcionamento do sistema não cessa, caso se opte por uma "parada" no itinerário. A Lógica não pede licença à teologia, bem como o encaminhamento das contradições do corpus social são inteligíveis independentemente da resolução no absoluto ${ }^{25}$.

A necessidade lógica do argumento nos autoriza a tirar algumas conclusões. Não existe sufocamento do outro em nome de panlogicismo algum. Esse "outro" é o fundo irredutível do sistema, a saber, a natureza em sua radical contingência. Ademais, a natureza não é apenas o outro da ideia - porém, muito mais radicalmente, consiste na ideia em alteridade consigo mesma (movimento que reúne, provisoria e essencialmente, sujeito e objeto). Só há processos. Nossa "constituição" mostra que a história mediatiza a natureza, surgindo, portanto, como natureza - na esfera da mediação ${ }^{26}$. O logos não captura a força cega da natureza; contudo, esta passa a surgir historicamente. A única naturalidade é o "aparecer": a mediação (relação) reorienta os termos singulares relacionados (a não-relação). A noção de "natureza original" não se sustenta, na medida em que ela é desde sempre já mediada, um passado sempre presente. Continuando, o espírito é o "outro em relação a si" - a chamada "segunda natureza" 27.

${ }^{25}$ KERVÉGAN, Jean-François. L'effectif et le rationnel - Hegel et l'esprit objectif. Paris: Vrin, 2007, p. 12 e ss, p. 392.

${ }^{26}$ ADORNO, Theodor. Dialectique négative. Paris: Payot, 2001, p. 277-278.

27 ŽIŽEK. Menos que nada. p. 314. A compreensão da substância como sujeito é ponto crucial para a filosofia hegeliana, ainda mais se se almejar uma reatualização de Hegel à luz da compreensão contemporânea com a ruptura. No que tange a história, cabe ao presente repor o tempo. A passagem canônica aparece no início da Fenomenologia: “(...) tudo depende desse ponto essencial: apreender e exprimir o Verdadeiro, não como substância, mas precisamente também como sujeito". Algumas linhas abaixo vê-se que há condições para o surgimento fenomenológico dessa figura: “(...) mas somente enquanto essa substância é movimento de se por a si mesma, ou é a mediação entre seu próprio devir outro e si mesma" (HEGEL. Phénoménologie I, p. 17 - em itálico no original; Fenomenologia, p. 32).

Evitando a leitura do sujeito como onisciência instrumentalizadora ou autossuficiente, acreditamos ser profícuo inseri-lo na discussão do surgimento do espírito. A substância 
Se Hegel deposita uma "fé" no homem isso se dá pela primazia da atividade. $\mathrm{O}$ inverso da questão não deixa de ser, porém, problemático: uma vez que o homem pode tudo, o que lhe resta a fazer e a ser? O contrapeso ao necessitarismo da substância se encontra justamente no ponto por ora desenvolvido, a saber, na orientação geral do hegelianismo segundo a qual "a substância é sujeito". Ora, "a substância é sujeito, mas somente em si" ${ }^{28}$. A substância é a história, mas cabe ao sujeito a função de coautoria nesse processo - não isento da contingência ou da processualidade. Emergente, o sujeito é sua verdade. É ele que cria a esfera ético-política - a necessidade é (e)levada ao reconhecimento, o que não pode acabar com a contingência.

\section{Paradigmas: revolução francesa e reforma}

A oscilação entre pessimismo e síntese onto-teológica a respeito da compreensão da história é exemplificada com clareza sobre a Revolução francesa. Por um lado, o jovem Hegel foi um entusiasta Revolução. Contudo, já na Fenomenologia do Espírito, sua postura parece ser dúbia. Ao seguir seus passos, percebemos o referencial para a compreensão racional da histórica deixar de ser a irrupção revolucionária e, abertamente, migrar para a revelação de Cristo e o advento da Reforma.

As críticas de Hegel ao "Terror", especialmente na Fenomenologia, ilustram sua posição. Se a Revolução francesa figura como a esperança que "os dois mundos [sejam] reconciliados; o céu desceu e se transportou à Terra", a desilusão não tardou a vir com a fúria da destruição.

se separa de si mesma, gerando um ponto de excesso que se autonomiza. Essa ruptura é instauradora do sujeito. O sujeito é portanto um intervalo da substância em seu movimento autorrelativo. A unidade se separa de si, gera a multiplicidade e retorna a si (o um cria o dois que volta ao um, do imediato ao imediato pela mediação). Essa assertiva é falha, na medida em que o um não é um, não se trata da coleta intacta da exteriorização, aliás, para sempre perdida, radicalmente contingente. Quando a unidade substancial se liquefaz na multidão de predicados caberá a um deles assumir a posição de sujeito e se (re)construir com os pressupostos. Assim sendo, não existe unidade: “(...) cada Um é um retorno-a-si-mesmo a partir do dois", a partir da separação inicial e imediata entre o Ser e sua experiência. O destino ao qual se retorna, o objeto de retorno, não preexiste ao ato de se retornar, sendo, insistamos, criado de maneira performativa. Está-se em portos hegelianos, nada seguros, a bem da verdade: nessas águas turvas o um equivale ao dois, em genuína identidade dos contrários. O um (a substância) é distante de si no dois (o sujeito) (ŽIŽEK. Menos que nada, p. 325-326).

Poeticamente, a referência é a "temporada no inferno" de Rimbaud, e seu "Eu é outro" (RIMBAUD, Arthur. Carta a Paul Demeny, 15 de maio de 1871. In: Euvres. Paris: La Pléiade, 1972, p. 250). O original em francês diz "Je est un autre". O verbo être, no sentido de ser, não concorda com o sujeito da frase, o "eu" (o correto seria "Je suis un autre"). Se em língua portuguesa tal erro pode passar desapercebido no uso cotidiano, em francês é questão de uma aberração gramatical, presente apenas na razão do poema.

28 D'HONDT. Hegel. p. 458. Em itálico no original. 
A universalidade abstrata, sem conteúdo, converteu-se politicamente em "fanatismo", expresso no "ódio ao particular": "A liberdade universal não pode portanto produzir nem uma obra positiva e tampouco um ato; não lhe resta senão o ato negativo; ela é somente a fúria da destruição"29.

Dito de outra maneira, a liberdade absoluta aplicada à sociedade finda por se negar, ou seja, nega os indivíduos que a sustentam. A liberdade é, portanto, inseparável da morte. Tal "liberdade universal" é entendida como desprovida de conteúdo, o que não a leva a lugar algum. Ela apenas nega um "si absolutamente vazio": "É assim a morte mais fria e mais baixa, sem maior significação do que cortar a cabeça de um repolho ou tomar um gole d'água" ${ }^{30}$. Hegel parece justificar a violência em nome da mudança de regime, mas, ao mesmo tempo, a condena em 1793.

Sua ambiguidade é ainda maior nos textos tardios. A Filosofia do direito aponta para a Revolução em um só tempo como "o primeiro espetáculo prodigioso desde que sabemos alguma coisa do gênero humano" e "o acontecimento mais espantoso e que mais fere a vista". Esses acontecimentos não seriam exclusivamente contingentes, na medida em que resultariam da vontade de aplicação imediata do universal. Demonstrariam, todavia, mais caos do que razão ${ }^{31}$.

Tal tendência já se deixava notar na Fenomenologia, onde se mostra que o espírito moral nasce após a reconciliação ${ }^{32}$. Tanto que as tendências reconciliatórias desembocaram no apoteótico "sim da reconciliação", onde os Eu's em questão abdicam de si mesmos diante do ser-aí posto, voltando-se a "Deus" ou simplesmente ao Espírito Absoluto ${ }^{33}$.

Posteriormente, a filosofia da história de Hegel toma a Reforma como ponto de inflexão e referência de periodização. A lição "fundamental" dos cursos de Hegel sobre a história consistiria em atrelar a possibilidade do choque revolucionário lá onde não houvera Reforma ${ }^{34}$. Essa citação nos ajudará, ao apontar para o que tinha sido resolvido pelo espírito:

A abstração do liberalismo assim atravessou o mundo latino a partir da França, mas esse mundo permaneceu ligado, pela escravidão religiosa, à falta de liberdade política. Pois é um falso princípio considerar que seja possível se desfazer de elos que entravam o direito e a liberdade sem que se emancipe a consciência moral e que uma Revolução seja possível sem Reforma ${ }^{35}$.

\footnotetext{
29 HEGEL. Phénoménologie II. p.129 e 135; Fenomenologia, p. 391 e 396.

30 Ibidem, p.136. Fenomenologia, p. 396.

31 HEGEL, G. W. F. Principes de la philosophie du droit. Paris: PUF, 1998, p. 315-316.

32 HEGEL. Phénoménologie II. p.141; Fenomenologia, p. 400.

33 Ibidem, p.198 e 200; Fenomenologia, p. 445 e 446.

34 LUKÁCS, Georg. Le Jeune Hegel II - sur les rapports de la dialectique et de l'économie. Paris: Gallimard, 1981, p. 237, 239 e 241.

35 HEGEL, G. W. F. Leçons sur la philosophie de l'histoire. Paris: Vrin, 1987, p. 344.
} 
O "elemento temporal" alemão já teria sido devidamente "corrigido" pela Reforma. A reconciliação teria sido operada; a contingência, extirpada: "o mundo protestante tinha igualmente consciência íntima de que, na reconciliação explicitada precedentemente, o princípio de um mais amplo desenvolvimento do direito estava presente" ${ }^{36}$.

Com efeito, Hegel afirma com todas as letras que seu esforço é o de construir uma "teodiceia" 37 . O "bem" é visto como uma "força eficaz", nomeada "Deus" - acima da qual "força alguma pode se colocar". Seus votos são de que "a história não seja nada além do que o Plano de sua Providência", pois "Deus governa o mundo": sua realização é a "história universal" e "apenas o ideal é o real". Assim remanejado, o processo soa unívoco: "A história universal é o progresso da consciência da liberdade: é esse progresso e sua necessidade interna que devemos aqui reconhecer" 38 .

A providência profanada esfacela o voluntarismo; o contragolpe é compreender a revelação de Cristo como "a chave da história universal" 39 , pois portadora de universalização.

Razão, Estado, História, Liberdade e Religião identificam-se, sem resto, ao invés de serem especificados em suas complexidades e pontos de contato: o "longo processo da história" é explicado enquanto a "aplicação do princípio [de liberdade] aos assuntos do mundo". Trata-se, sem dúvida, de uma realização da filosofia, mas cujo sentido não pode se eximir de disputas. A diferença espacial em um mesmo bloco de tempo é também um princípio de dominação. O "progresso da consciência da liberdade" se presentifica pouco a pouco do Oriente rumo ao Ocidente: "os orientais souberam que apenas um homem é livre, o mundo grego e romano que alguns são livres, nós sabemos que todos os homens são livres, o homem enquanto homem é livre".

Hegel acrescenta que cada "estágio" corresponde a uma "época". A divisão da história em períodos por ele estabelecida é ainda mais explícita ao fim do livro. Em apenas uma frase, o "contorno inteiro da história" se condensa: "O sol se levanta no Oriente". O sol físico não deverá mais aterrorizar o "sol interior", uma vez conquistado o engendramento da "liberdade subjetiva". O "objeto" diante do qual devemos nos inclinar no reino fenomenal é o "Estado" - pois "o Estado é a Ideia universal, a vida espiritual universal", em face da qual os indivíduos desenvolvem "uma relação de confiança e de

36 Ibidem, p. 338-339.

37 HEGEL. La raison. p. 67-68.

38 Ibidem, p. 67-68, 100-101 e 84.

39 Ibidem, p. 65. 
costume", até que a "substância" possa coincidir com o "elemento singular" 40 .

Percebe-se, finalmente, que perspectiva transformadora alguma tem lugar em um regime do aparecer regulamentado não pelo fim (ou desaparecer, seu outro), mas pela anulação dos termos anteriores - de certa forma um fim, mas que dá lugar não à renovação, e sim à identidade estanque, quer seja o logos, quer seja o Estado, quer seja a teologia sob moldes identitários. Eis a astúcia fechada. Essa vertente interpretativa nos autoriza a recolocar a questão da contingência - que clama por seus direitos. Ou melhor, os impõe.

\section{Contingência e sistema}

A dualidade da história em Hegel pode ser percebida segundo duas tendências - o estranhamento e a interiorização redundante. Dessa orientação decorre outro dualismo do movimento - uma autoprodução que se exterioriza (a auto-apresentação da substância ou a realidade efetiva como verdade e certeza) e a sua apresentação "sob a forma do devir livre e submetido ao acaso", ou o estranhamento do espírito junto aos entes ${ }^{41}$. Segundo Marcuse, ambas acepções confrontam as duas tendências encontradas em Hegel: uma para a imobilização da história (interiorização determinada pelo saber absoluto que finda com o movimento) e outra que visa a manter a historicidade (estranhamento na contingência $)^{42}$.

Algumas alternativas se delineiam no horizonte, uma vez que o problema passa a ser o da abertura ou fechamento do hegelianismo. Não nos cabe aqui esgotar tão rica e complexa querela ${ }^{43}$. Somente, nos limitaremos a apontar para alguns caminhos por nós trilhados que

40 Ibidem, p. 84 e 279-281. No outro extremo, a substância não coincide com o singular - a não ser em termos especulativos. Ela o produz, mantendo portanto uma relação negativa. A separação inicial nada mais é do que a "verdade", desde que posta em e engendrada no movimento. A análise já é síntese. Contudo, precisa-se de tempo. Na psicanálise o "conhecimento" não repousa no analista - mas no analisando (que, por seu turno, não "conhece" isoladamente).

41 HEGEL. Phénoménologie II. p. 311; Fenomenologia, p. 530

42 MARCUSE, Herbert. L'Ontologie de Hegel et la théorie de l'historicité. Paris: Gallimard, 1991, p. 319 e 320.

43 Acompanhar de perto o debate realizado no Brasil acerca da contingência em Hegel, estabelecido sobretudo - mas não só - no Rio Grande do Sul, exigiria um esforço à parte em termos de argumentação e de levantamento bibliográfico. Tal perspectiva sistemática não cabe no escopo deste trabalho - ainda que se tente apontar para o espraiamento da Ciência da Lógica para os demais setores da obra hegeliana, o esforço principal ora suscitado consiste no debate acerca dos cursos sobre filosofia da história. Tal crítica, a bem da verdade, já circula na filosofia desde Schelling (mas também Feuerbach e Schopenhauer), e posteriormente chegando a Kierkegaard, Marx e Nietzsche (cf. LÖWITH, Karl. De Hegel à Nietzsche. Paris: Gallimard/ Tel, 2003, p. 224-232). 


\section{privilegiam a contingência. São eles as considerações do jovem Marcuse} em seu doutoramento, onde a Lógica é lida à luz da Fenomenologia e seu conceito de "vida" 44 ; e também o esforço de se compreender a relativa imprevisibilidade da ação (sobretudo política), o que nos leva a tentar

Nesse sentido, o tratamento de questões ligadas ao espírito finito mostraria sua ligação intrínseca (ou seja, o panlogicismo seria a base tanto para o sufocamento do indivíduo quanto o fim da contingência e da natureza). Trata-se, todavia, de não só apontar para os "impensados" de Hegel, mas de verificar sua efetividade, aquilo que seu pensamento é capaz. Ora, negar a contingência na letra hegeliana redunda em postura externa ao texto. A questão corretamente posta deve indagar sobre seu papel no bojo do sistema. Ainda assim, conforme descreve Eduardo Luft, chega-se a aporias. Como demonstra este autor, o movimento de autodeterminação do absoluto acaba por escamotear a função da contingência. Seu papel só seria legítimo caso participasse da determinação do racional. O ser relativo sempre se desfará ao retornar ao absoluto, uma vez que não possui seu fundamento em si. Receberia o contingente, da parte de Hegel, um, por assim dizer, "tratamento externo"? Pois sua resolução não oferece resistência à efetivação do absoluto. Ora, por outro lado, o possível não se põe em seus próprios termos? Leiamos Hegel, no derradeiro volume da grande Lógica: "A unidade da substância é sua relação de necessidade; mas de tal maneira ela é somente necessidade interior; na medida em que ela se põe pelo momento da negatividade absoluta, se torna identidade manifesta ou posta, e portanto liberdade, que é a identidade do conceito" (Science de la Logique, La Doctrine du Concept. Paris: Aubier-Montaigne, 1981, p. 41-42).

O ponto chave, defende Luft, é a ambiguidade da passagem da "necessidade relativa" à "necessidade absoluta" (LUFT, Eduardo. Para uma crítica interna ao sistema de Hegel. Porto Alegre: Editora PUCRS, 1995, p. 133, 134 e 176). Cirne-Lima recorre a Kant para fazer do contingente uma vontade, ou seja, as diversas possibilidades não são exteriores ao racional. Sua busca de uma racionalidade aberta recupera o dever-ser (Sollen) como instância que pressupõe e realiza a contingência; deve o sistema conter, e "em pesos iguais", necessidade e contingência (CINE-LIMA, Carlos. Sobre a contradição. Porto Alegre: Editora PUCRS, 1993, p. 94,100 e 104).

O logos se converte em paideia, sem fim. O pensamento hegeliano se vê cambiado em um método a posteriori; assim, não é absurdo postular que a distinção entre "necessidade relativa" e "necessidade absoluta" é menos lógica do que cronológica.

Esperamos, ao nosso modo, deixar isto mais claro com a eleição do conceito de "liberação", ao invés da liberdade. Sobre o "livre-arbítrio", tecemos rápidas considerações: um mundo transparente à vontade seria uma falsa solução à questão da contingência, recaindo na metafísica da presença. Em termos pragmáticos, e aí se retoma de certa forma Hegel, o arbítrio é o momento final de uma processualidade que se passa para além ou a despeito do entendimento, dele se fazendo valer (via "astúcia") - perspectiva que condiz, contemporaneamente, com a compreensão do sujeito como "efeito" ou separação da substância. De maneira geral, os comentadores que se debruçam sobre este tema privilegiam visadas sistemáticas, ou seja, aceitam o desenvolvimento pleno do conceito de liberdade (mesmo que privilegiando, por vezes, a centralidade da figura da alteridade, explicitada na Doutrina da Essência). Sobre a questão da contingência, consultar igualmente JULIÃO, José Nicolau. "A Filosofia da História como o lugar de efetivação da liberdade no Sistema da Ciência Hegeliano". In: Revista Veritas, Porto Alegre: PUCRS, 59(1) (jan.-abr. 2014), p. 86105; WOHLFART, João Alberto. "Necessidade e liberdade na Ciência da Lógica". In: Revista Veritas,Porto Alegre: PUCRS, 60(2) (maio-ago. 2015), e55-e80; MÜLLER, Marcos Lutz. "A gênese lógica do conceito especulativo de liberdade". In: Analytica, Rio de Janeiro: UFRJ, (1993), p. 77-141.

44 Marcuse acredita que relacionar a "ideia de conhecimento" com a "ideia de absoluto" pela mediação da vida rompe com a concepção de absoluto. Ocorre que na Lógica a história é, quando muito, o acúmulo de estados de conhecimento, ao contrário das mudanças dos entes na Fenomenologia. Se a Fenomenologia pede a organização ontológica da Lógica, a Lógica por seu turno se vê revigorada com o princípio de ser como mobilidade disposto na 
conceituar o telos desta não na liberdade, mas enquanto possibilidade. O intuito é não sufocar o potencial agônico de forças em presença em nome de um princípio superior, o que só poderia legitimar, ao invés de elucidar, a chamada "história dos vencedores" 45.

Em todo caso, a estratégia por ora adotada, a saber, a leitura não metafísica ou calcada na independência do espírito objetivo, compartilha com os comentadores supracitados a preocupação de remodelar o sistema hegeliano, expondo-o de outra maneira. Assim, o sentido materialista, capaz de gerar efeitos de verdade para além da época de Hegel, é captado na anterioridade da natureza. Com todo rigor, a temática é pós-hegeliana (contingência e possibilidade); o tratamento do material, por isso mesmo, é não ortodoxo: trata-se de fazer funcionar as engrenagens do sistema alimentando-o de questões, em princípio, a ele exteriores ${ }^{46}$. Em linhas gerais, a abertura da história e a disputa política.

Mesmo em termos estritamente hegelianos, o jovem Marcuse crê que todo prosseguimento da Ciência da Lógica constatado na Doutrina do Conceito não poderia superar os ganhos da lógica objetiva. Dito de outra maneira, a "realidade efetiva" não pode de forma alguma passar a uma estrutura "ainda mais real". Trata-se, isto sim, de uma "repetição" de realidade ${ }^{47}$. O próprio Hegel declara que a necessidade já é em si o conceito ${ }^{48}$. Eis a razão pela qual Marcuse pensa que a passagem da necessidade ao conceito é uma falsa passagem ${ }^{49}$.

Em guisa de elucidação, é preciso lançar luz sobre a Ciência da Lógica, de modo que possamos recuperar o fundo da discussão sobre o papel da contingência e os limites do conceito de liberdade. Desde já nos desculpamos do caráter sucinto da exposição, mas o fundamental é situar o argumentário, indicando as bases de nossos desenvolvimentos.

Fenomenologia: o ser efetivo e positivo é "cindido", o que implica a compreensão do ser-aí como "desigualdade". Em outras palavras, a vida entendida como historicizada é eleita o fundamento do Ser, em detrimento do Eu dotado de pensamento. A visada de Marcuse começa pela crítica do postulado da Lógica onde o ser e pensamento coincidem. Nessa obra, a unidade primordial do ser é anterior a toda diferença. Contudo, "esse retorno à oposição primordial de subjetividade e da objetividade" é a instância que permite a compreensão de uma história não fatalista. Desde então, a história adquire um sentido específico, a saber, seu desenrolar ocorre no regime do estranhamento - seja ele no devir da natureza ou no ato de pensamento (MARCUSE. L'Ontologie de Hegel. p. 210, 211, 198, 203-205).

45 A título ilustrativo, a colocação de Gramsci ganha relevo, já que, de acordo esse autor, "só se pode prever a luta", e não seus "momentos concretos" (GRAMSCI, Antonio. Cahiers de prison, VI, VII, VIII et IX. Tomo II. Paris: Gallimard, 1992, p. 17).

46 Se o sistema é "fechado", a perspectiva de abertura não abandona o método de determinação recíproca.

47 MARCUSE. L'Ontologie de Hegel. p. 97-98.

48 HEGEL. Encyclopédie I. p. 581.

49 MARCUSE. L'Ontologie de Hegel. p. 107. 
O ser se interioriza e se torna essência ao mover-se a partir de si mesmo; neste ponto, o absoluto é a essência ${ }^{50}$ : a essência adquirida pela mediação não torna o saber qualquer coisa de exterior ao ser; muito pelo contrário, este processo é o movimento do ser.

Jean-Hyppolite é da opinião de que haveria "três pulsações do Logos" e seus respectivos ciclos em cada um dos volumes da Lógica: o ser, a essência e o conceito ${ }^{51}$. A tripartição da reflexão - como reflexão colocadora, reflexão exterior e reflexão de determinação/ determinante - é a pedra de toque para a compreensão de todas as tríades da Doutrina da Essência. A problemática é tanto mais capital quanto, insistamos, a sistemática aspirada não é diretamente a mesma de Hegel. Se é possível se criticar o fato de lançar mão de determinações que originariamente aparecem em outros contextos (como a universalidade e a determinação do processo), constata-se que a forma de absoluto que intervém na Doutrina da Essência é a cisão entre o interior e o exterior.

Ao fim das contas, a processualidade não é eliminada, já que o universal constrói uma outra relação com os entes. Isso não poderia impedir uma resposta hegeliana à questão prática que se impõe desde então aos sujeitos: qual é o papel da exterioridade (histórica) em nossos atos? A pressuposição de si na exterioridade enquanto figura ou momento da negação determinada nos parece indicar uma boa pista.

O retorno a si segundo um gesto tautológico inclui a exterioridade dilacerada no processo de doação de sentido - de si e do mundo, concomitantemente. Ou seja, a decomposição de um objeto em partes não é capaz, por si mesma, de lhe devolver uma unidade provisória; fora de si, positividade alguma reúne a coisa. Assim sendo, há história na medida em que há a pressuposição de um campo produtor de objetividade.

A partir de então, o absoluto é a totalidade ainda não determinada, e efetivo e possível guardam uma diferença apenas formal: são seres-aí postos na contingência. Em seguida, a contingência lhes atribuirá uma determinação, o que explica a "efetividade real" ou "aquilo pelo que apareceram paralelamente possibilidade real e necessidade relativa"; em última instância, a reflexão desembocará na "necessidade absoluta", equivalente à "possibilidade e efetividade absolutas" 52 . Note-se que neste ponto é a primeira vez no decorrer da Lógica onde uma determinação não coloca em xeque os termos relacionados.

\footnotetext{
50 HEGEL. Doctrine de l'essence. p. 2.

51 HYPPOLITE. Logique et existence. p. 220.

52 HEGEL. Doctrine de l'essence. p. 248.
} 


\section{Lição e aprendizado}

Relacionada à tradição filosófica, a "astúcia da razão" se deixa compreender, esperemos que não de maneira ardilosa, por pelo menos quatro chaves de leitura: a subsunção absoluta que a tudo identifica, chegando ao ponto de acabar com a própria história (racionalismo); a postura subjetiva do cinismo, impotente - e indiferente - diante do curso do mundo (cinismo); o curso da história ao fim e ao cabo corresponderia a uma teodiceia, realizando a vontade de Deus (providencialismo); o espírito se realiza necessariamente, não podendo o homem senão aceitar o que lhe sucede (fatalismo). Note-se que as quatro hipóteses de trabalho são intercambiantes, já que o absoluto pode ser tanto mecânico quanto teológico; cinismo e fatalismo são momentos de um mesmo movimento, cuja explicação pode repousar, uma vez mais, quer seja na razão quer seja na teologia ${ }^{53}$. Afora isso, inseriremos o privilégio absoluto da contingência, ensejando nova fronteira a explorar.

Nossa estratégia consiste em primeiramente apresentar a astúcia da razão inserida nas temáticas acima de filosofia da história para, após, sugerir outra apropriação. Ao se evitar a leitura da filosofia da história hegeliana em geral, e da astúcia da razão em particular, como a realização da "história universal", mostraremos como a razão que se efetiva chega a uma nova relação consigo mesma no seio da alteridade. Não exteriores ao corpus hegeliano, o dinamismo da negatividade, bem como sua experiência, erigem-se como perspectivas hermenêuticas de validação.

A crítica aos limites a priori da razão em Kant atravessa o reino da história. Para o filósofo de Königsberg, a regularidade na história humana não é constatada imediatamente. Assim, uma "liberdade individual" é captada como um acontecimento natural, ou seja, seguindo leis. Por isso a natureza é o "fio condutor" da aventura humana na terra. O mais derrisório ato e a mais mesquinha paixão não mostram racionalidade, eis porque se apela à natureza. Se há racionalidade no homem, cabe às "disposições naturais" realiza-la não no indivíduo, mas na espécie e ao longo do tempo. Em Kant vê-se a teoria da "insocial sociabilidade": a inclinação (e necessidade) de se viver em sociedade é acompanhada pela repulsão, o que põe em risco todo projeto societal. A natureza se serve dos homens para seu próprio fim ${ }^{54}$.

Por isso Hegel põe a identidade entre razão e história: "a história é o produto da razão eterna e a razão determinou suas grandes revoluções".

${ }^{53}$ BOUTON, Christophe. "Hegel et l'antinomie de l'histoire". In: Lectures de Hegel. Organização Olivier Tinland. Paris: Le Livre de Poche, 2005, p. 300-305.

54 KANT, Immanuel. La Philosophie de l'histoire (Opuscules). Paris: Denoël, 1980, p. 26-28 e 31. 
Prolongamento da ação, a história escapa aos homens. De agora em diante será preciso contar com a manifestação temporal da razão ${ }^{55}$. Para Hegel,

o ponto de vista da história filosófica não é retirado abstratamente da multidão dos outros pontos de vista gerais e não pode ser compreendido se se faz abstração dos demais. Seu princípio espiritual é a totalidade de todos os pontos de vista ${ }^{56}$.

O pessimismo de Hegel, por si só, o demarca do otimismo das Luzes. Isso fica patente com a consciência da negatividade da história e do sofrimento dos indivíduos. Mesmo na Razão na história, a história é considerada como um "altar onde foram sacrificados a felicidade dos povos, a sabedoria dos Estados e a virtude dos indivíduos" 57 .

De toda maneira, a história é captada como o domínio da contingência: o pessimismo aí se exprime por sua caracterização como "um imenso quadro feito de acontecimentos e ações", "uma mistura multicolorida que nos carrega" ${ }^{58}$. É esse aspecto que interpela a filosofia; a análise exige a categoria de mudança, que acarreta igualmente as de aparição e desaparição. O dilaceramento do mundo a nada leva, por enquanto:

Nós marchamos em meio a ruínas daquilo que um dia exceleu. O mais nobre e o mais belo nos foram arrancados pela história: as paixões humanas o arruinou. Tudo parece voltado ao desaparecimento, nada persiste. Todos os viajantes experimentaram essa melancolia. Quem viu as ruínas de Cartago, Palmira, Persépolis, Roma, sem refletir sobre a caducidade dos impérios e dos homens, sem o luto dessa vida passada possante e rica?

Hegel acusa os homens e suas paixões: as "ruínas" não poderiam ser obra da natureza, atribuindo-se à "vontade humana" um papel. Tal "espetáculo", continua Hegel, por pouco não leva a uma "aflição moral e uma revolta de espírito do bem"59.

O homem com demasiada autoestima vive no "domínio das paixões", onde se realiza sua "particularidade". A teoria hegeliana lhe atribui, sim, um quinhão de felicidade; o homem realiza sua "finitude" quando é confrontado com "seu Outro" e com ele se reconcilia em seguida. Todavia, sarcástico, ou melhor, pessimista, Hegel leva adiante seu raciocínio: "Na consideração da história, pode-se adotar também o ponto de vista da

\footnotetext{
55 BOUTON. Hegel et l'antinomie. p. 304-305.

56 HEGEL. La Raison. p. 151.

57 Ibidem, p. 103.

58 Ibidem, p. 53-54.

59 Ibidem, p. 54 e 103.
} 
felicidade - mas a história não é o lugar da felicidade". A frase seguinte é ainda mais tocante: "Os períodos de felicidade nela não são senão páginas em branco", pois a "satisfação" residiria em objetivos que superam largamente a perspectiva individual ${ }^{60}$.

\section{Astúcia da razão - ou quem ludibria quem}

Lê-se no parágrafo 347 da Filosofia do direito que o "povo históricomundial" só "pode nela [a história] fazer época uma vez", pois logo em seguida vem a queda - tal povo sai de cena, rei morto, rei posto. A ideia de golpe destinal aproxima assim a compreensão da história com a tragédia grega ${ }^{61}$. Os deuses agem por meio de outros, mensageiros e eventos encarregados de fazer passar a hybris; acontecimentos se submetem a uma jurisdição superior. Da mesma maneira que os personagens das peças antigas, os protagonistas da história são "heróis"62, ou Napoleão ou César. Sua personalidade, carregada pelo interesse do universal, está à altura do cumprimento da ação; o novo espírito pode ser implementado.

A "astúcia da razão" maquina: "pode-se denominar astúcia da razão o fato que ela deixa agir em seu lugar as paixões, de maneira que somente este é o meio pelo qual ela chega à existência, experimentando perdas e sofrendo estragos" 63 .

O que faz a razão? Levantemos duas questões: engana a paixão, dirigindo-a, e se impõe? Ou estaria ela ciente de que sua realização é sua perda, ou seja, seu contrário?

Nessa primeira hipótese haveria uma causa irredutível? Se assim for, tratar-se-ia de elemento que confere direção ao devir, numa relação de dominância com demais determinações (ações se realizam)? Estaríamos diante do processo de efetivação, eis o irredutível. Pouco importa, aliás, o saber ou a ignorância do processo, uma vez que o "contrário" alçado ao posto de efetivo é processual, ou seja, um resultado - e portanto algo não volitivo. Ou lidar-se-ia com uma finalidade desde sempre prevista? Nessa linha, o irredutível é a razão que determina sem se deixar determinar, avessa a encontros - ela os cambia, por certo, sem todavia por eles se deixar contaminar.

Uma segunda chave ainda se nos apresenta como plausível: não é a razão "ela mesma" que se nos apresenta ao cabo da cadeia de efetivação. Antes, a razão se liga a seu pressuposto (natural) para que chegue à sua verdade (graças à alteridade). Isso nos leva a uma teoria da ação, que

\footnotetext{
60 Ibidem, p.115-116.

61 HEGEL. Philosophie du droit. p. 414.

62 HEGEL. La Raison. p. 121.

63 Ibidem, p. 129.
} 
une o não controle da exterioridade ao irracional da paixão. Seu produto, sempre a refazer, consiste na razão. Sua efetivação no tempo confere inteligibilidade à história.

O desafio é sair do impasse segundo o qual interior e exterior opõemse de maneira excludente, cuja lógica do "ou isso ou aquilo" passa ao largo da dialética. Dicotomias como atividade e passividade, bem como positividade e negatividade ou paixão subjetiva e realidade objetiva, abandonam sua dimensão estanque. O interior espiritual nutre relação de tensão criadora com a exterioridade do mundo. Esse o marco que proporciona ao espírito um para si (mediante sua própria negação) na alteridade. A "morada no negativo" tem aqui seu quinhão ${ }^{64}$.

Paradoxalmente, o caos da paixão é produtor de ordem, ou, sem juízo de valor, de estabilidade autorrelativa característica do efetivo. As paixões individuais constroem um sistema de dependência universal, mesmo se o objetivo de cada indivíduo não ultrapassar o egoísmo ${ }^{65}$. Desse ponto de partida emergem tanto a compaixão e a satisfação das demandas de outrem, quanto as contradições imanentes ao funcionamento do socius e suas eventuais resoluções - jamais definitivas.

Segundo Bouton, está-se diante de uma noção "equívoca": um curso independente da ação que, em um só tempo, não só desmantela o racionalismo em função do fatalismo da ação, mas também instrumentaliza os indivíduos. Nessa última perspectiva, uma "força subjetivo-espiritual" cumpre o que desde sempre foi ${ }^{66}$. Ao escrever que "nada de grande nesse mundo se realiza sem paixão"67, Hegel dota a paixão de efetividade. Resta saber se o irracional se cala diante do panlogicismo ou se é prolongado (e realizado) graças à razão, quando a relação consigo se estabiliza.

Postular que os indivíduos são atravessados pela paixão não redunda na perda completa da individualidade em prol da dominação, mas no elogio do negativo, do ausente que irrompe ${ }^{68}$. Tampouco a tarefa de "realizar o que sempre foi" não consiste necessariamente na ode a alguma sorte de paraíso perdido. Pelo contrário, o dispositivo hegeliano da astúcia da razão é filosófico (e não apenas "historicista", no sentido relativista de "cada época com sua verdade") na medida em que a repetição de exteriorização e interiorização é a condição mesma de toda a ação - trata-se, em suma, da explicitação teórica do linguajar comum contido no "agir" (identidade teórico-especulativa da ação). A eternidade

\footnotetext{
64 Ver o segundo tomo da Phénoménologie, p. 313; Fenomenologia, p. 531

65 HEGEL. Philosophie du droit. p. 291.

66 BOUTON. Hegel et l'antinomie. p. 324.

67 HEGEL. La Raison. p. 108-109.

68 Ainda que fenômenos psíquicos como a despersonalização não sejam estranhos ao reino das paixões (melhor: sua "estranheza" assim se determina).
} 
da razão se revela no real do espírito objetivo: a revelação depende do efetivo, não sendo seu "Outro" - mas o efetivo advindo em alteridade consigo mesmo. Seu ser-aí é manifestação de si, não apontando para um além ou aquém do mundo ${ }^{69}$.

A paixão representa a concentração de desejo dos indivíduos que conseguem se dar objetivos e assim se projetam no tempo, abrindo portanto suas próprias individualidades ao curso do tempo ${ }^{70}$. Vê-se, assim, que o tempo é o horizonte de sentido onde se aproximam e se condensam as determinações. A história é essa repetição, mas a repetição é histórica, ou seja, forçosamente contingente.

De relações tão contingentes quanto as engendradas pelas paixões surge algo maior, a própria história. O decisivo é portanto a própria definição de história: relações contingentes e contudo determinadas, ou leis cegas?

O automovimento da sociedade se ergue como "tribunal do mundo", em compreensão colada ao desenvolvimento do espírito objetivo. Inicialmente, o voltar a si do espírito requer a consciência da liberdade. Todavia, uma vez mais, nos parece que a volta a si comporta o momento de efetivação, distinto do destino.

Ademais, a história do mundo não é o mero tribunal da potência do espírito, quer dizer, a necessidade abstrata e desprovida de razão de um destino cego[;] ao contrário, porque o espírito é em si e para si razão, porque o ser para si desta é, em espírito, saber, ela é o desenvolvimento, necessário apenas pelo conceito da liberdade do espírito, dos momentos da razão e, nisso, da consciência de si e da liberdade do espírito ${ }^{71}$.

69 HEGEL. Encyclopédie I. p. 393; e Doctrine de l'essence. p. 247.

70 Que se pense na paixão hegeliana em paralelo ao "entusiasmo" kantiano em face do sublime. Os espectadores da Revolução Francesa são saudados por Kant em seu desinteresse. Sua "maneira de pensar" os "trai publicamente" uma vez que na oposição diante do acontecimento se exprime uma "disposição", uma "tomada de posição" universal que não se constitui em um fato, sendo a presença do próprio progresso. Kant prossegue acrescentando que "pouco importa" a vitória ou a derrocada daí advindas e vivas em um povo "rico de espírito". Isso acorre segundo "uma solidariedade de aspiração que frisa o entusiasmo e cuja manifestação mesma comporta um perigo; essa solidariedade por consequência não pode ter outra causa senão uma disposição moral do gênero humano" (KANT. Opuscules. p. 170-171). Tal entusiasmo não é propriamente o sublime, mas uma de suas modalidades. Pois se trata justamente mais de uma disposição subjetiva diante de uma experiência do que a consideração de um objeto. Uma definição plausível do sublime seria que a imaginação não chega a conferir um objeto à intuição, a fornecer uma representação à ideia de razão; essa impotência abre a via à significação, por sua finalidade, a saber, a de concordar com as ideias da razão; a faculdade de julgar reflexiva é substituída por esse processo e sentimos a humanidade em nós. Ou, ainda, no "delírio báquico" tal como descrito na Phénoménologie I (HEGEL, p. 40-41; Fenomenologia, p.50): da relação exterior (contrariedade), os objetos assumem uma relação essencial de contradição. Os objetos se destroem e o infinito vem à tona como fundamento dinâmico. Todos os membros se comunicam pela ebriedade. O ser-aí, positivo e particular, se conserva como reminiscência desse momento ou interiorização de si.

71 HEGEL. Philosophie du droit. p.407, p. 410, p. 411 e p. 412. 


\section{Conclusão: libertar a liberdade?}

Pôr uma aporia é já "fazer a topologia de uma solução"72, ensina Bernard Mabille em seu filosofar "à provação pela contingência". Tomamos a liberdade de completar: desde que a dita "prova" não seja refém da adequação ao existente, com dados viciados. "Libertar a liberdade" pode soar vago, mas apostamos que o gesto reflexivo ${ }^{73}$ é produtivo de novas realidades, tanto efetivas quanto simbólicas. A "presença" de Hegel deve se furtar de sentindo ou ter o sentido furtado, na violência de uma apropriação. Encarada como imediaticidade, se dá à mediação. Não sendo um conceito positivo, a liberdade é, antes, objeto de disputa. A própria liberdade não seria "absoluta", no sentido de "em si e para si". Indireta, ela é mediada, processual e resultado. Em outras palavras, pode ser determinada como a liberdade de uma coação - o que lhe confere um sentido, sempre provisório, e um, por assim dizer, "lugar" na história, no regime do aparecer em suas repetições.

Incorremos o risco de desmantelar qualquer tentativa de sistematização e assim perder a razão de ser do encadeamento hegeliano. Ao longo do trajeto, todavia, nos deparamos numa verdadeira encruzilhada entre uma "substância" spinozista (toda ação sendo transparente a si mesma, temos como resultado um necessitarismo), o quietismo teológico do elogio da Reforma e as raias da Filosofia do direito (onde a negatividade se vê parada em benefício da representação do Estado como uma Instituição separada). Portanto, foi preciso encontrar as boas ferramentas para engendrar um pensamento da contingência no seio do sistema hegeliano. A dinâmica a apreender mantem-se, logo, entre a determinação daquilo que acontece e a determinação do estado de coisas presente. Dito de outra maneira, lidamos com a emergência de uma situação que se consolida ou se torna efetiva.

Uma dúvida nos assalta. Seria esse arranjo kantiano, no sentido de barrar a realização da ideia e assim retomar a crítica dos limites da razão? Em caso afirmativo, a liberdade é apenas um horizonte regulador, uma projeção da imaginação - ainda que tenha a função pragmática de orientar a ação. No kantismo, a teoria física é insuficiente para a compreensão da história, o que demanda uma teleologia, pois a natureza não concorda com a lei moral; a distinção é entre "necessidade" e "dever ser", respectivamente ${ }^{74}$.

72 MABILLE, Bernard. Hegel - l'Épreuve de la contingence. Paris: Aubier, 1999, p. 18.

73 O ato de reflexão reativa o passado, trazendo à tona a dimensão de um "passado-presente" cujo estatuto é "intemporal".

74 KANT, Immanuel. Critique de la faculté de juger. Paris: Vrin, 1993, p. 340 e 405. 
Que se desfaçam os mal-entendidos: uma filosofia da mediação põe seus pressupostos. O decisivo portanto é retrabalhar a liberdade. Apreender a realidade significa apreendê-la em suas falhas, em sua finitude: se o todo é verdadeiro, o não todo aí se inclui - e não é por isso menos verdadeiro.

A passagem de Kant a Hegel deve ser encarada não nos termos de um limite epistemológico, onde as formas da intuição a priori impedem o conhecimento da coisa em si; mas, isto sim, como uma determinação ontológica, onde a própria coisa é contingente e inconsistente. O real distorce nosso acesso ao em si, eis a fórmula do saber absoluto. O em si é sempre já mediado, posto na lacuna entre sujeito e objeto ${ }^{75}$. Em Kant, o ponto de vista do entendimento separa, via imaginação, conceitos da realidade. Já em Hegel, a "abstração" faz parte da constituição da coisa, que nunca pode aparecer pura (como em Marx, o valor é objetivamente parte da forma mercadoria). Há um salto especulativo: a inconsistência da ideia do objeto faz parte do próprio objeto. Não se trata de ativamente sintetizar um conteúdo que afeta o sujeito, porém de libertar o objeto fazendo-o sujeito - ser passivo de ponta a ponta e sair de si, vislumbrando o mundo das mediações ${ }^{76}$.

O ente deve se dizer por si mesmo, e não pela acumulação de enunciados e de regras de enunciação em nome de um a priorismo do raciocínio modal. O efetivo não carece de passar a um plano superior, onde perca o vir a ser ou movimento que o levou a esta efetividade específica. Nesse sentido, a passagem à liberdade nos parece logicamente um falso problema, na medida em que uma relação de determinação recíproca onde os elementos voltam a si já se efetua positivamente o princípio do absoluto ${ }^{77}$. Por isso, em termos concretos, no intuito de vivificar o hegelianismo, propomos uma dialética entre necessidade e possibilidade - onde esta última adquire o papel de absoluto, de "em si" e "para si". Ao invés de "liberdade", optamos pela "liberação".

Por conseguinte, necessidade e possibilidade não podem excluir-se mutuamente e de maneira estanque. Por isso não basta inverter imediatamente o enunciado. A "necessidade da contingência" deve ser acompanhada pela "contingência da necessidade", que se deixa determinar - ou melhor, se modifica no curso de sua efetivação, tornando o processo "aberto" e a "condição de possibilidade" algo "movente". A necessidade existiria ao mesmo tempo como uma efetividade ou inscrição na realidade e como uma relação (a presença é necessária; presenças se

75 ŽIŽEK. Menos que nada. p. 239.

${ }^{76}$ Ibidem, p. 245-246 e 251.

77 HYPPOLITE. In: HEGEL. Phénoménologie I. p. 19-20. 
encontram, se relacionam). No outro polo, a possibilidade é uma negação determinada que abre uma via no seio da realidade e se faz reconhecer, modificando o regime do aparecer. Além disso, a noção de relação é compreendida tanto como uma origem (determinação que não se deixa esgotar de maneira alguma em determinismo), quanto uma abertura pois se trata de uma exposição às contingências no curso de sua eclosão.

Como decorrência, temos uma relação de tensão com o curso da história, cuja postura teórica lida com dois aspectos: de um lado, ela é construída como uma interrogação acerca dos limites das particularidades num contexto de determinação recíproca; de outro, o pensamento vê-se desde então descentrado e conduzido às disputas práticas da luta, tornando-se estratégico.

A necessidade da astúcia é válida ao se fazer outra. Seu sentido imanente é a não previsibilidade da ação que relança o ponto de partida (paradoxalmente determinado em sua liberdade). A necessidade como categoria do passado chega como uma construção que não pode ser demolida; a possibilidade, categoria do futuro, é ainda uma potência; fechando o "ciclo", a "realidade, categoria do presente, (...) associa indissoluvelmente necessidade e possibilidade"78. Passível de continuação e aberto às apostas no interior de conjunturas, o "possível" é um acontecimento historicizado, uma ruptura que faz problema. Condenados estamos à conjugação de temporalidades disparatadas: os objetivos visados pelas diferentes ações sendo diversos, seus meios de efetivação também os são; longe de uma perspectiva de adequação, essa exteriorização é ainda necessariamente sobredeterminada pelas novas relações exteriores e pelo simples fato de expor-se à contingência.

O termo "utópico" deve ser alçado à sua ideia, ao se lançar mão da distinção entre utopia concreta e utopia abstrata - entre privilégio do presente e idealização. Os fins não justificam os meios (a injustiça pode ser, quando muito, explicada, mas não legitimada); tampouco o meio existe por si só (nosso estar no mundo traz consequências). Dialeticamente ligados, meios e fins constituem objeto de crítica. Dito de outra maneira, é preciso assumir o abismo entre os meios e os fins e, a partir daí, confrontar, a cada vez, a realidade com a finalidade. Até que a próxima astúcia nos tire para dançar.

\section{Referências}

ADORNO, T. Dialectique négative. Tradução Gérard Coffin, Joëlle Masson, Olivier Masson, Alain Renault e Dagmar Trousson. Paris: Payot, 2001.

78 BENSAÏD. Marx. p. 395-398. 
BALIBAR, E. La Crainte des masses - Politique et philosophie avant et après Marx. Paris: Éditions Galilée, 1997.

BAVARESCO, Agemir; OLIVEIRA COSTA, André. "Estatuto lógico da alteridade hegeliana". In: Síntese - Rev. de Filosofia, Belo Horizonte: Faculdade Jesuíta, 38(120), 27-53.

BENSAÏD, D. Marx o intempestivo - grandezas e misérias de uma aventura crítica. Tradução Luiz Cavalcanti de Menezes Guerra. Rio de Janeiro: Civilização Brasileira, 1999.

BOUTON, C. "Hegel et l'antinomie de l'histoire". In: Lectures de Hegel. Organização Olivier Tinland. Paris: Le Livre de Poche, 2005.

CHÂTELET, F. "Hegel". In: La Philosophie et l'histoire (1780-1880) - Histoire de la philosophie, tomo V. Organizado por François Châtelet, Wanda Bannour, Jean-Luc Dallemagne, Sami Naïr, Alexis Philonenko e Nicos Poulantzas. Paris: Hachette Littératures, 2000.

CINE-LIMA, Carlos. Sobre a contradição. Porto Alegre: Editora PUCRS, 1993.

. Depois de Hegel. Caxias do Sul: EDUCS, 2006.

D'HONDT, J. Hegel - philosophie de l'histoire vivante. Paris: PUF/Épiméthée, 1966.

ENGELS, F.; MARX, K. La Sainte famille. In: Euvres III - Philosophie. Tradução Maximilien Rubel, Louis Évrard, Louis Janover. Paris: Gallimard/Pléiade, 1982.

ENGELS, F. Carta de 21 de setembro de 1890 a Joseph Bloch. In: MARX, K.; ENGELS, F. Études philosophiques. Tradução Guy Besse. Paris: Éditions Sociales, 1977.

GRAMSCI, A. Cahiers de prison, VI, VII, VIII et IX. Tomo II. Tradução de Monique Aymard e Paolo Fulchignogni. Paris: Gallimard, 1992.

HEGEL, G. W. F. Premiers écrits (Francfort 1797-1800). Tradução Olivier Depré. Paris: Vrin, 1997.

. Phénoménologie de l'esprit. Tomos I e II. Tradução Jean Hyppolite. Paris: $\overline{\text { Aubier, }} 1975$ e 1983.

. Fenomenologia do espírito. Tradução de Paulo Meneses, com a colaboração de Karl-Heinz Efken e José Nogueira Machado. Petrópolis/Bragança Paulista: Editora Vozes/Editora Universitária São Francisco, 2013.

. Science de la logique. Livro I: La Logique objetive, tomo I, Doctrine de l'être; tomo II, Doctrine de l'essence. Livro II: La Logique subjetive ou Doctrine du concept. Tradução Pierre-Jean Labarrière e Gwendoline Jarczyk. Paris: Aubier-Montaigne, 1987, 1982 e 1981.

. Ciência da Lógica - excertos. Tradução Marco Aurélio Werle. São Paulo: Barcarolla, 2011.

. Encyclopédie des sciences philosophiques. Tomo I, La Science de la logique.

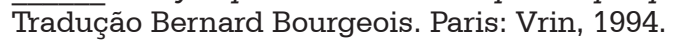

. Enciclopédia das Ciências Filosóficas em compêndio. Tomo I, A Ciência da Lógica. Tradução Paulo Meneses, com colaboração de padre José Machado. São Paulo: Edições Loyola, 1995.

. Enciclopédia das ciências filosóficas em compêndio. Tomo 3, Filosofia do espírito. Tradução Paulo Menezes, com colaboração de padre José Machado. São Paulo: Loyola, 1995. 
HEGEL, G. W. F. Principes de la philosophie du droit. Tradução Jean-François Kervégan. Paris: PUF/Fondements de la politique, 1998.

. Filosofia do Direito (Linhas Fundamentais da Filosofia do Direito ou Direito Natural e Ciência do Estado em Compêndio). Tradução Paulo Meneses, Agemir Bavaresco, Alfredo Moraes, Danilo V.-C. R. M. Costa, Greice Ane Barbieri e Paulo Roberto Konzen. Recife: UNICAP; São Paulo: Loyola; São Leopoldo: UNISINOS, 2010. 1987. . Leçons sur la philosophie de l'histoire. Tradução Jean Gibelin. Paris: J. Vrin, . La Raison dans l'Histoire. Tradução Kostas Papaioannou. Paris: UGE/Plon, 1965. Filosofia da História. Tradução Maria Rodrigues e Hans Harden. Brasília: Editora Universidade de Brasília, 1999.

HORKHEIMER, M. Les Débuts de la philosophie bourgeoise de l'histoire. Tradução Denis Authier. Paris: Payot, 1974.

HYPPOLITE, J. Génesis y estructura de la Fenomenología del espíritu de Hegel. Tradução Francisco Fernández Buey. Barcelona: Ediciones Península, 1974. 1991.

. Logique et existence - Essai sur la logique de Hegel. Paris: PUF/Épiméthée,

JULIÃO, José Nicolau. "A Filosofia da História como o lugar de efetivação da liberdade no Sistema da Ciência Hegeliano". In: Revista Veritas, Porto Alegre: PUCRS, 59(1) (jan.-abr. 2014), p. 86-105.

KANT, I. La Philosophie de l'histoire (Opuscules). Tradução Jean-Louis Ferrier. Paris: Denoël/Gonthier, 1980.

. Critique de la faculté de juger. Tradução Alexis Philonenko. Paris: Vrin, 1993.

KERVÉGAN, J-F. L'effectif et le rationnel - Hegel et l'esprit objectif. Paris: Vrin, 2007.

LÖWITH, K. Histoire et Salut - les présupposés théologiques de la philosophie de l'histoire. Tradução Marie-Christine Challiol-Gillet, Sylvie Hurstel e Jean-François Kervégan. Paris: Gallimard, 2002.

. De Hegel à Nietzsche. Tradução Rémi Laureillard. Paris: Gallimard/Tel, 2003.

LUFT, Eduardo. Para uma crítica interna ao sistema de Hegel. Porto Alegre: Editora PUCRS, 1995.

LUKÁCS, G. Le Jeune Hegel II - sur les rapports de la dialectique et de l'économie. Tradução Guy Haarscher e Robert Legros. Paris: Gallimard, 1981.

MABILLE, B. Hegel - l'Épreuve de la contingence. Paris: Aubier, 1999.

MARCUSE, H. L'Ontologie de Hegel et la théorie de l'historicité. Tradução Gérard Raulet e Henri-Alexis Baatsch. Paris: Gallimard/Tel, 1991.

- Raison et révolution - Hegel et la naissance de la théorie sociale. Tradução $\overline{\text { Robert }}$ Castel e Pierre-Henri Gonthier. Paris: Minuit, 1968.

MARX, K. Critique de l'État hégélien - Manuscrit de 1843. Tradução Kostas Papaioannou. Paris: UGE-10/18, 1976.

MÜLLER, Marcos Lutz. "A gênese lógica do conceito especulativo de liberdade". In: Analytica, Rio de Janeiro: UFRJ, (1993), p. 77-141.

RICEUR, P. Temps et récit I e III. Paris: Éditions du Seuil, 1983 e 1985. 
RIMBAUD, A. Carta a Paul Demeny, 15 de maio de 1871. In: Euvres. Paris: Gallimard/ La Pléiade, 1972.

WOHLFART, João Alberto. "Necessidade e liberdade na Ciência da Lógica". In: Revista Veritas, Porto Alegre: PUCRS, 60(2) (maio-ago. 2015), e55-e80.

ŽIŽEK, S. Menos que nada - Hegel e a sombra do materialismo dialético. Tradução Rogério Bettoni. São Paulo: Boitempo Editorial, 2013.

\section{Endereço postal:}

Departamento de comunicação social PUC-Rio

Rua Marquês de São Vicente, 225, Gávea

Rio de Janeiro, RJ, Brasil

Data de recebimento: 15/01/2014

Data de aceite: 14/03/2016 